\title{
Interpersonal communication, voting behaviour and influence in an election campaign: The 2009 German elections
}

\author{
Moreno Mancosu ${ }^{1, *}$ \\ 1 Collegio Carlo Alberto, Moncalieri (TO), Italy \\ * moreno.mancosu@carloalberto.org
}

\begin{abstract}
Interpersonal influence - the process by which people change their idea according to the ideas of others - is a crucial mechanism that forges political agreement among citizens. By using data from the 2009 German Longitudinal Election Study short-term campaign panel, it will be tested how this strategy contributes to changing citizens' ideas in the proximity of the 2009 Bundestag elections in Germany. Results of fixed-effect logistic regression models confirm the findings in previous literature, showing evidences consistent with influence effects. It is also suggested that the social circle of discussants alters the way in which people are influenced. Propensities to change vote choice, in fact, are boosted by the exposure to disagreeing strong ties, such as relatives and spouse/partner.
\end{abstract}

\section{Keywords}

social influence, political behaviour, Germany, longitudinal analysis, fixed-effect models

\section{Interpersonale Kommunikation, Wahlverhalten und Einflussnahme während einer Wahlkampagne: die Wahl in Deutschland im Jahr 2009}

\section{Zusammenfassung}

Die Interpersonale Einflussnahme - beziehungsweise das Phänomen der Meinungsänderung einer Person aufgrund der Meinungen anderer - ist ein Mechanismus, der die politische Einigung von Bürgern entscheidend beeinflussen kann. Auf Basis der Daten des 2009 durchgeführten Kurzzeit-Panels der German Longitudinal Election Study wird analysiert, wie dieses Phänomen die Meinung der Bürger hinsichtlich der Bundestagswahl in Deutschland im Jahr 2009 beeinflusst hat. In der Tat bestätigen die Ergebnisse der logistischen Regressionsmodelle mit fixen Effekten, wie es bereits die Erkenntnisse aus der Literatur zeigen, dass das Phänomen der Meinungsänderung zu entscheidenden Beeinflussungen führen kann. Unter anderem wird vermutet, dass das soziale Umfeld der an der Diskussion Beteiligten bestimmt, in welcher Art und Weise sie beeinflusst werden können. Die Bereitschaft, sein eigenes Wahlvorhaben zu ändern, findet ihre Ursache vor allem in Auseinandersetzungen mit Personen aus dem engsten Beziehungsumfeld, wie z. B. mit Verwandten oder Ehepartnern.

\section{Schlüsselwörter}

soziale Einflussnahme, Wahlverhalten, Deutschland, Panelanalysis, fixed-effects models

\section{Acknowledgement}

The author wants to thank the anonymous reviewers, Rüdiger Schmitt-Beck, and Adriano Cataldo for their helpful comments and support.

The author has declared that no competing interests exist. 


\section{Introduction}

Interpersonal communication has proven to be an important element in contemporary democracies, affecting both the stability and change in individuals' voting behaviour. According to the so-called social logic of politics, rather than an individual calculus, voting can be seen as a social activity in which discussion networks represent the environment where people structure their attitudes and political preferences (Berelson, et al. 1954; Huckfeldt/Sprague 1995; Huckfeldt et al. 2004; Zuckerman 2005).

There are many ways in which this complex set of relations contributes to the shaping of citizens' voting behaviour. Different works stressed the role of influence mechanisms in shaping patterns of agreement among citizens during election campaigns. Broadly speaking, we can define influence as the mechanism in which two disagreeing individuals reach a situation of political agreement, that is, when one out of the two (or both) changes their idea (see Rolfe 2009; 20I2; Bello/Rolfe 20I4). As these behaviours are relatively fine-textured, many studies (Klofstad 2007; Fowler et al. 20II; Lazer 20II; Lomi et al. 20II; Mollenhorst et al. 2008) suggested the employment of longitudinal data. For instance, using a 4-wave panel collected during the 20IO British elections, Bello and Rolfe (2014) show that influence does actually represent a relevant process during an election campaign, which contributes to explain electoral volatility.

By employing a 6-wave panel collected during the 2009 German Bundestag electoral campaign, this study aims to test whether the Germans' voting choices are conditioned by interpersonal influence strategies. With respect to previous studies, the article presents several distinctive traits. First, the study aims at treating, both theoretically and empirically, a topic which, quite surprisingly, has been rarely systematically tested in the literature, namely the effects that different types of relations can have on influence: we will ask ourselves whether closer relations lead people to reach an agreement, and then to influence/being influenced in a stronger way. Second, this study investigates how the acceleration of the campaign can lead to differences in influence effects. In this case, we ask ourselves whether vicinity to the final voting decision, attained by increasing interest and political communication among citizens, boosts the likelihood of adopting behaviours that lead to agreement, such as influence. In this respect, we focus on the political context of the 2009 campaign of the German Bundestag and highlight its peculiarities.

From the methodological viewpoint, the testing strategy is based on fixed-effect (or within-effects) models. With respect to models employed in the literature (see, for instance, Bello/Rolfe 20I4), such a regression model, focusing only on within-individual variations, allows one to automatically control for omitted/unobserved variables, drastically reducing spurious correlations or alternative explanations and yielding more robust theoretical conclusions (Wooldridge, 2OI2).

Results suggest that influence effects are present among German voters. Moreover, it is argued that among member of the same familiar circle, the process of influence is more likely. The effect of closeness to the election day on influence mechanisms, on the contrary, does not seem to be confirmed by the data.

\section{Political influence: Definitions and effects on vote choice}

The dynamics of political agreement/disagreement in social networks have been largely analysed since the seminal works on electoral behaviour (Berelson et al. I957; Zuckerman 2005). In the literature, it is basically possible to find four theoretically relevant interactional settings that depict this dynamic. The first has been deepened by Columbia scholars (Lazarsfeld et al. 1948; Berelson et al. 1954) who depicted it as the most common situation that is possible to observe. According to this view, people used to live in a more or less stable network of politically like-minded discussants (Zuckerman 2005; Huckfeldt et al. 2004). Given the availability of information in two different periods, $t_{\mathrm{o}}$ and $t_{1}$, a large share of citizens who are embedded in such a network is expected to be measured in agreement both in $t_{o}$ and $t_{r}$.

Although quite common, this situation is not the only one that we can obtain from political networks data. It has been argued (Huckfeldt et al. 2004) that persistent disagreement, that is, a constant situation of discordant political ideas in a communication network, is a condition that is easily observable in political networks. It has been reported, indeed, how people can sustain a certain level of political disagreement that persists in time. This phenomenon is shown to be consistent, both theoretically and empirically, at certain network-related conditions (see Huckfeldt et al. 2004; Mutz 2002).

Given a situation of interpersonal disagreement, a person can avoid interacting with his/her discussant or influencing (and being influenced by) his/her political position. These two theoretical settings are defined as selection and influence (Bello/Rolfe 2OI4). As demonstrated since Festinger's studies, indeed, disagreement leads to stressful situations and, consequently, to cognitive dissonance reduction strategies (Festinger 1957). According to selection, one may decide to interrupt political relations with a disagreeing discussant, selecting his/her network on political similarity (Bello/Rolfe 20I4). The selection process does not usually lead to behaviours that undermine the relations among people in every dimension; for 
instance, "[s]election of political discussants does not necessarily mean ending existing relationships or befriending all Liberal Democrats that one meets; it can be as simple as choosing to sit at the opposite end of the table from politically conservative Aunt Edna at family gatherings' ${ }^{\prime}$.

This study, however, is particularly focused on the process of influence, that is, the strategy according to which, after having confronted respective opinions, people reach an agreement about political matters. '[O] ne person may change his or her mind as a result of new information, social pressure, imitation of peers or some other psychological mechanism associated with making conditional choices' (Bello/Rolfe 2OI4). It is possible to recognize basically two different types of influence. Influence can be seen as a process in which one of the two discussants of the dyad stays in his/her own position and the other one switches towards the first, or, given different political positions in $t_{o}$, two discussants reach some sort of intermediate position in $t_{\mathrm{r}}$. In any case, the baseline to assess evidence compatible with the mechanism is as follows: given a previous situation of disagreement and after some sort of opinion exchange by means of political communication, an agreement is reached by means of someone who changes his/her political opinion. Numerous studies since the earliest works on the topic (Berelson et al. 1954; Latané I996; Huckfeldt et al. 2005; Bello/Rolfe 20I4) stressed the strict relationship between disagreement and the likelihood of changing vote choice. An hypothesis that can support our argument can read as follows: an individual in a dyad will be more likely to change his/her vote choice if, previously, the dyad was a disagreeing one. In other words, the probability of changing vote choice is conditional on previous situations of disagreement in the dyad. Influence, however, is not merely related to the dyad itself: 'Influence may depend less on dyadic disagreement with a single discussant and more on the distribution of attitudes within the larger political discussion network' (Bello/Rolfe 20I4). In this case, as the data at our disposal can only account for the relation between an individual and his/her main discussant (that is, the person with whom the former talks more about politics; see below), we can only infer hypotheses on a dyadic process rather than on a network one. Although this shortcoming can be identified as a failure of the testing strategy (the original theoretical framework concerning network disagreement is not fully tested), we can take this dearth of data as an opportunity to debate against ourselves. The theoretical argument in the lit-

I It is important to stress that, from the empirical point of view, selection means that, being in disagreement with a discussant in a certain moment of the campaign leads one to change her discussant in the subsequent time. Unfortunately, the data at our disposal do not allow to test this expectations, not providing a variable that univocally identifies discussant's identity. erature (Bello/Rolfe 20I4) tests for a relation between a person and his/her interactional environment, thus assuming that the actual mechanism of conversion, which is dyadic, is implied in the empirical regularity given by the relation between network disagreement and switching of political attitudes. In this study, on the contrary, the testing strategy is fully committed in researching a relation between the change of vote choice of an individual $\mathrm{X}$ and the disagreement he/she has experienced with another individual (and not a network) Y.

Moreover, network-related characteristics of one's discussants can increase or reduce the propensity of adopting a selection strategy. A successful way to disentangle the differences that can appear in a network is discriminating among different levels of cohesiveness that different sections of an ego-network ${ }^{2}$ can have (Huckfeldt et al. 1995).

According to Granovetterian theory (Granovetter 1973), the distinction between weak and strong ties is fundamental in understanding the complex pattern of communication networks. From one side, strong, cohesive ties produce an environment in which everyone knows each other. As a consequence, ideas and arguments are enclosed in that network. Conversely, dealing with weak ties means being exposed to less cohesive patterns of communication; this can lead to being exposed to different ideas and new experiences. On the other hand, however, the very concept of weak ties posits that these discussants are often relatively unimportant with respect to strong ties. Huckfeldt et al. (I995) simplified this complex pattern of weak and strong relationships by talking about cohesive social groups (that is, groups characterized by a high prevalence of strong ties, principally the family) and groups lying outside this closed social bubble (Erisen/Erisen 20I2), also called non-cohesive social groups, such as friends, neighbours and coworkers (Huckfeldt et al. 1995).

It is known that in normal conditions, people who are part of cohesive social groups exert stronger coercive effects on ego with respect to people who are part of non-cohesive circles (see, for instance, Mutz 2002; Mutz/Mondak 2006; Faas/Schmitt-Beck 20IO). We can thus expect that discussants who are relatives provide higher levels of political coercion as relations are more intimate and ties are generally stronger with respect to non-familiar ones (Huckfeldt et al. I995; Huckfeldt/ Sprague i995). Surprisingly, little evidence has been devoted to finding an effect of the social circle to which two discussants belong in mediating influence effect. If disagreement is more difficult to be sustained in a familiar environment, we can expect that attempts to recompose

2 Troughout the article, "ego" is defined as the reference individual of the theoretical argument, or the respondent in a survey, and "ego network" is the personal network of this individual, namely, the other actors ego has ties with. 
an agreement situation will be more intense. As a result, disagreement with relatives will exert a stronger effect in the likelihood of vote change compared with that of non-relatives.

Temporal proximity to the election day could affect the way in which citizens try to influence (or accept being influenced by) others. Numerous studies in the literature have investigated the effect that election campaigns can have on vote choices (Gelman/King 1993; Krosnick/Kinder 1990). With reference to classic studies on political participation (Berelson et al. 1954), we know that acceleration of the campaign and closeness to the election day can affect political discussions and involvement in the campaign. Because strategies that aim to forge agreement are conditioned to interpersonal relations (if there is no discussion, there is no interpersonal influence whatsoever), it is possible to argue that the timing of the campaign, namely, the closeness to the election day, boosts the relation between disagreement and vote switching.

Of course, this hypothesis can be weakened by the actual political competition that characterizes our case study: a campaign that fails (partly or completely) to stimulate voters' involvement and discussion will be less likely to encourage people to forge agreement or even to deal with it. In this respect, it is important to stress the particular circumstances in which the election campaign of 2009 took place. The 2005 German elections, which came after a red-green government and a vivid election campaign, led the country to a grand coalition, comprising the socialist party (SPD) and the conservatives (CDU/ CSU). This result led to the inability of the two main parties of the German political spectrum to attack each other in the 2009 campaign (having shared governmental responsibilities for the previous four years). The literature concerning the 2009 Bundestag elections shows how parties partly failed to activate and/or mobilize voters, leading to lenient differences in the campaign with respect to, for instance, the 2005 campaign (Krewel et al. 20II; Partheymüller/Schmitt-Beck 20I2; Johnston et al. 2014). This particular situation could have weakened the magnitude of the relation between campaign effects and interpersonal influence.

\section{Data, methods and models}

\subsection{Data}

The 2009 German Longitudinal Election Study (GLES) short-term campaign panel (Schmitt-Beck et al. 20I2) represents an almost unique longitudinal dataset for electoral studies of continental Europe: respondents were interviewed, up to six times, with the CAWI method during a I4-week period from IO July 2009 (the starting date of the first wave) to the election day, 27 September 2009 (corresponding to the last day of the 6-wave data collection). In every wave, which was held roughly every two weeks, respondents were asked to provide information about their voting behaviour (namely, the party they were going to vote for) and the strength of their partisanship. In order to measure the degree of respondents' political sophistication, the level of interest in the outcome of the federal election was surveyed. In particular, partisanship strength and political sophistication were identified as useful variables to control for alternative explanations of patterns of disagreement and vote switching 3 .

Information about the perceived behaviour of the 'main discussant' was also collected. The main discussant was identified as the person with whom the respondent had recently talked more about politics. The main discussant usually holds characteristics that differ from the remaining discussants. First, it is more likely that this discussant belongs to an intimate social circle, such as the relatives circle (Huckfeldt et al. 1995). Second, he/ she usually presents higher levels of agreement with the respondent. It is important to stress that the main discussant concept does not necessarily overlap with an intimate relationship. The main discussant can be picked among non-cohesive social groups, (Huckfeldt et al. 1995; Klofstad et al. 2009) or rather, intimate discussants may not be chosen by the respondent to be a main political discussant too. The main difference between intimacy and the role of the main discussant, with reference to our aims, is that an individual could be more interested in reaching an agreement with an intimate person (because of the psychological strain that a situation of disagreement could have on him/her) than with a non-intimate one.

Respondents were asked to report the perceived vote choice of their main discussant and the type of relationship that the respondents and their discussants had (whether they were spouses, relatives, friends, co-workers or neighbours).

The combination between respondent's and (perceived) discussant's vote choice ${ }^{4}$ produces the main independent variable, the dyadic disagreement, which is I when respondents' and discussants' vote choices are equal, and it is o otherwise. In order to construct the variable, only non-missing observations have been maintained (thus erasing respondents * wave combinations ${ }^{5}$ in which the respondent was undecided and/or the discussant's opinion was not declared by the respondent).

3 Several studies (Converse 1966; Zaller 1992; Bello/Rolfe 2014) hypothesize that political involvement and partisanship can lead to lower propensities of changing vote choices.

4 In both cases, the 'Second vote' was taken into consideration.

5 A dataset on which a fixed-effect model is performed is reshaped so that every observation does not represent an individual but rather an individual ${ }^{*}$ wave combination. Every individual, thus, is spread on the number of waves he/she participated in. 


\subsection{Methods}

Similar to previous works (Lyons 20II; Christakis/Fowler $2007 ; 2008)$, the present study aims at modelling the relation between disagreement and vote switching as an evidence compatible with the presence of an interpersonal influence mechanism. The testing strategy is partly borrowed from Bello and Rolfe (20I4), who argued a methodological way to avoid problems of discussant selection that could undermine our estimates (Noel/Nyham 20II). A potential drawback of Bello and Rolfe's strategy, however, is modelling this relation in time by employing multilevel random-intercept models. It has been shown (Wooldridge, 20I2) that this modelling strategy presents less convincing estimates when estimating ceteris paribus effects. In other words, random-effect models would not be so reliable in estimating effects that are assumed to unfold in time, given that their magnitude and significance could be inflated by omitted variable problems. This study employs a much more reliable modelling strategy-the logistic fixed-effect (FE) model, also known as the 'unobserved effects model' or 'within-effects model' (Wooldridge 20I2; Allison 2009).

The main argument behind FE models is that, in order to control for individual characteristics that do not change in the observation window, the simplest strategy is to use each individual as his/her own control (Allison 2009). Technically, the FE model includes a dummy variable for every individual. In this way, it allows us to control for omitted/unobserved variables that do not change within every individual during the observational window. The main consequence of this analytic strategy is that we have estimates of effects concerning only within-person changes over time. This is crucial given that our hypotheses are based on the fact that disagreement with others produces differences within each respondent along different waves.

Using only within-individual variations, the $\mathrm{FE}$ model maximizes the robustness of our results against spuriousness (Dillipane 20I4); since it controls for every measured or unmeasured time-invariant characteristic of every individual, alternative explanations based on these properties are automatically excluded. For instance, one may expect that younger or higher-educated people are more (or less) prone to endogenously change their vote choice, with or without external stimuli. By means of the FE model, these alternative explanations are automatically ruled out and solely within variation is estimated.

In logistic FE models, given that the dependent variable is a dichotomous one, the intercept, as well as cases in which the dependent variable does not change in the observation window, are expunged by the analysis (Allison 2009). Rather than a shortcoming, the smaller amount of observations, when leading to statistically significant estimates, suggests more robust results ${ }^{6}$.

\subsection{Models}

Three fixed-effect models - one for every hypothesis are fitted. As stressed above, our baseline hypothesis is that an influence effect is recognizable. Thus, a relation between dyadic disagreement and change of vote choice is sought.

Following Bello and Rolfe's testing strategy (2014), we model a non-directional influence effect. In other words, no explicit assumption is made on the direction towards which the respondent will vote when he/ she changes his/her vote choice. The only expectation that is tested is that electoral volatility is fuelled by disagreement with a discussant. This methodological device avoids many issues that could arise by assuming a certain relationship among voters, their discussants and each party (Jackman/Vavreck 20IO; Rolfe/Bello 20I4). We can plausibly infer (together with other works, see Schmitt-Beck/Partheymüller 20I6; Mancosu/Vezzoni 2OI7; Rolfe/Bello 2OI4) that the increasing volatility of people who perceive disagreement in a certain moment actually leads these people toward the party voted by their political discussant. However, a it must be stressed that a non-directional strategy does not give us the "smoking gun" of the fact that ego is actually going into the direction of alter's vote choice (we will deal with this limitation in the last paragraph).

The dependent variable of the models, thus, is the change of vote choice: the variable is equal to $\mathrm{I}$ when a respondent declares the intention to vote for a party in wave $_{n-1}$ and for another one in wave ${ }_{n}$, and it is equal to o otherwise. Disagreement is measured so that it is equal to I when the respondent and his/her discussant disagree (that is, when the vote choice reported by the respondent and the perceived vote choice of the discussant are different) and is o otherwise. As a further control, the social circle of the discussant is added in this model. Disagreement and social circle of the main discussant are both lagged (that is, collected in the previous wave of the panel with respect to the dependent variable) in order to avoid endogeneity or reverse-causality doubts. Moreover, we control for alternative explanations by adding two variables reporting, on a 5-point scale, the respondent's interest in the outcome of the election (from 'Completely unimportant' to 'Very important') and the

6 Conventionally, scholars in the econometric literature (Wooldridge 2OI2) report the Hausman test that compares the estimates of a random-effect and a fixed-effect model. If there is a significant discrepancy, the fixed-effect model is preferred. If there is no difference, the random-effect model is preferred. Hausman tests performed on the three models that follow turned out to be highly significant. Thus, we can conclude that our fixed-effect estimates are preferable with respect to random-effect ones. 
respondent's strength of partisanship (from 'Very weak' to 'Very strong'). Overall, the number of non-missing respondents is equal to 1,629 . Among these people, 202 people were retained in the fixed-effect models for an average of 3.3 waves, producing 668 observations. Model I can be thus designed as follows:

$\mathrm{p}($ CHANGE_VOTE $\mathrm{t} / \mathrm{t}-1=1)=\mathrm{DISAG}_{\mathrm{t}-1}+\mathrm{SOC} \_\mathrm{CIR}_{\mathrm{t}-1}+$ PID_STRENGTH $\mathrm{t}_{\mathrm{t}-1}+$ INTER $_{\mathrm{t}}+\mathrm{WV}$

where CHANGE_VOTE $\mathrm{t}_{\mathrm{t} t-1}$ is the dependent variable (equal to I when the respondent changed his/her vote from $\mathrm{t}-\mathrm{I}$ to $\mathrm{t}$ and o otherwise); $\mathrm{DISAG}_{\mathrm{t}-1}$ is I when the respondent's reported and the discussant's perceived vote choice differ and o otherwise; SOC_CIR th-1 $_{\text {in }}$ is the social circle to which the discussant belongs (according to the respondent's ego network), coded as relative (spouse/ partner and relatives, equal to o) and non-relative (all other relations, equal to I); PID_STRENGTH $\mathrm{H}_{\mathrm{t}-1}$ and INTER $R_{t}$ are controls for alternative explanations (respectively, party identification strength and interest in the outcome of the elections could contribute to negatively affecting vote switching)7. Finally, WV is a set of dummies taking into account the panel waves.

The second model takes into account the hypothesis according to which discussants belonging to closer social circles (and being assumed as closer social ties) are those who exert a stronger effect on respondents. The second model will thus take into account a two-way interaction between disagreement with and social circle of the main discussant.

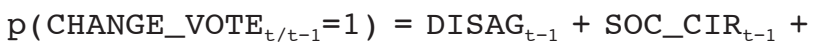
$\mathrm{DISAG}_{\mathrm{t}-1}$ *SOC_CIR $\mathrm{S}_{\mathrm{t}-1}+$ PID_STRENGTH $\mathrm{t}_{-1}+$ INTER $_{\mathrm{t}}+$ WV.

Model 2 is identical to model I except for the interaction term DISAG ${ }_{\mathrm{t}-1}$ *SOC_CIR $\mathrm{S}_{\mathrm{t}-1}$. Interactions test whether the effect of one predictor variable is different at different values of another predictor variable. In this case, an interaction term is useful to test whether the effect of disagreement in t-I on the likelihood of change vote choice is different at different degrees of intimacy between ego and alter. Interactions change dramatically the interpretation of our models, also for what concerns the so-called "main effects" (the plain variables

7 These two control variables are affected by data-related problems. The PID variable has been collected only in waves I, 3 and 5. Since it is relatively stable in time (Campbell et al. 1960; Budge et al. 2010) and represents a control variable in our model, it has been decided to operate a last observation carried forward (LOCF) imputation (Siddiqui/Ali 1998) to keep observations also in waves 2 and 4 . Interest in the outcome of the elections variable was collected from wave- 2 to wave-6. Producing a lagged variable would thus have erased the wave- 2 information for all the cases in the data. It has been thus decided not to lag the variable. that compose the interaction and that must be inserted in the model, see Gelman/Hill 2007). A main effect can be interpreted as the effect of the variable when the other variable in the interaction is equal to $\mathrm{O}$. Thus, $\mathrm{DISAG}_{\mathrm{t}-1}$ represents the effect of disagreement on vote switching in the case of a relative discussant. Moreover, the effect of the interacted variable (in a dummy-dummy interaction) is the effect when both variables are I. Thus, DISAG $_{t-1}$ *SOC_CIR $\mathrm{S}_{\mathrm{t}-1}$ is the effect of disagreement in the case of a non-relative one (see Gelman/Hill 2007, 34. For an equivalent design see Mancosu/Vezzoni 2017).

The third model takes into account the timing of the election and the effect that it could exert on the relation between disagreement among discussants and respondent switching. In order to test this hypothesis, another two-way interaction is inserted in the model, leading to the model that follows:

$\mathrm{p}\left(\right.$ CHANGE_VOTE $\left._{\mathrm{t} / \mathrm{t}-1}=1\right)=\mathrm{DISAG}_{\mathrm{t}-1}+$ SOC_CIR $_{\mathrm{t}-1}+$

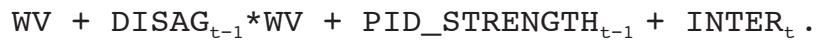

In this case, the interaction term $\mathrm{DISAG}_{\mathrm{t}-1} * \mathrm{WV}$ tells us whether the effect of the relation between disagreement and vote switching is stronger at the end of the campaign with respect to that in the beginning of it. In Model 3, the wave variable, instead of being a set of dummies, has been inserted in the model as a continuous score in order to facilitate the readability of the estimates. A version of Model 3 with a wave inserted as a set of dummies leads to substantively identical results.

\section{Results}

\subsection{Descriptive results}

Since results of longitudinal data can often be quite obscure, it was decided that descriptive results coming from the data would be provided. These results help us in sketching descriptively what happens in the sample, in terms of vote switching and disagreement (our two main variables), during the six months of the observational window. First of all, it is important to assess the relative size of the phenomenon that we are investigating. Table I presents, in absolute values and percentages, the proportion of respondents in the 2009 GLES data who have, at least once, declared to be in disagreement with their main discussant or changed their vote choice.

As it is possible to see from Table I, disagreement is, all in all, quite a common experience among German voters (more than half of the sample [55.6\%] declared to have experienced, at least once during the observational window, disagreement with their main discussant). Another important trend that the 2009 GLES data show is concerned with the situations of disagreement. 
Table 1: Number (and percentage) of respondents who have ever disagreed or changed vote choices during the six months before the 2009 elections

\begin{tabular}{lcc}
\hline & \multicolumn{2}{c}{$\begin{array}{c}\text { Respondent who have, at } \\
\text { least one time }\end{array}$} \\
& N & $\%$ \\
\hline Disagreed & 906 & 55.6 \\
Changed vote choice & 298 & 18.3 \\
\hline Total & \multicolumn{3}{c}{1,629} \\
\hline
\end{tabular}

Table 2 shows a transition matrix in which, given an agreement/disagreement situation in a certain moment of the campaign, the distribution of the same situation in the following wave of data collection is shown ${ }^{8}$.

Table 2: Transition matrix from agreement/disagreement in $\mathrm{T}_{1}$ to agreement/disagreement in $\mathrm{T}_{2}$

\begin{tabular}{llll}
\hline $\mathbf{T}_{1}$ & \multicolumn{2}{c}{$\mathbf{T}_{2}$} & Total \\
& Agreement & Disagreement & \\
\hline Agreement & $83.4(\mathrm{n}=882)$ & $16.6(\mathrm{n}=176)$ & 100.0 \\
Disagreement & $22.9(\mathrm{n}=171)$ & $77.1(\mathrm{n}=576)$ & 100.0 \\
\hline Total & 58.3 & 41.7 & $\begin{array}{l}100.0 \\
\left(\mathrm{n}=1,805^{*}\right)\end{array}$ \\
\hline
\end{tabular}

* in a transition matrix, the total number of changes can be higher than the number or respondents (namely, a respondent can pass from agreement to disagreement more than one time)

Given a situation of disagreement in $\mathrm{t}_{\mathrm{r}}$, more than three out of four individuals $(77 \%)$ remain in disagreement with their main discussant. On the other side, $83 \%$ of those who were in agreement remain in agreement with their main discussant. The possible substantive interpretation for these results is that, although stable, the level of disagreement tends to slightly decline as long as we approach the election day, that is, as long as the campaign accelerates-this trend is consistent with other descriptive results (see Figure I) that report a decline in disagreeing people, from wave-I to wave- 6 , of about 3 percentage points.

Data concerning our dependent variable (Table I) show that the change of vote choice is quite rare. Less

8 As it is possible to see, the absolute frequency of dyads passing from agreeable to disagreeable situations is roughly similar (actually, those who pass from agreeable to disagreeable situations are slightly more). This, however, does not change the interpretation of our models, which investigate whether the disagreement in a point in time leads to a change of vote intention in the subsequent moment.
Figure 1: Percentage of respondents reporting disagreement with their discussant - per wave (GLES 2009 data)

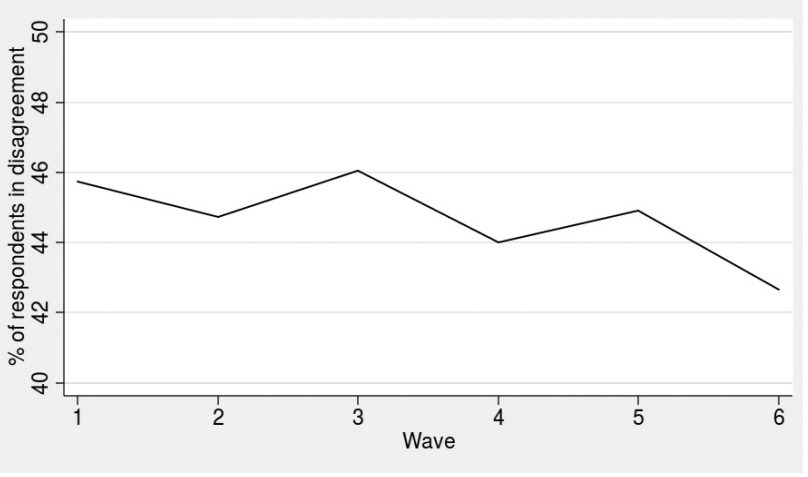

than one out of five people ( $18.3 \%$ ) of the sample experience a change in vote choice during the six months before the elections.

Of course, these descriptive results indicate nothing about the hypothesized relation between disagreement and vote switching. The only possible assertion is that the decline of disagreement is consistent with one or more agreement-seeking mechanisms, such as influence. The next paragraph will test the hypotheses exposed in previous paragraphs by employing a set of fixed-effect models.

\subsection{Fixed-effect models results}

The three fixed-effect models are presented in Table 3. Model I shows that among the individuals who have changed their vote choice during the observational window, there is a significant effect of the disagreement between the respondent and discussant in the previous wave on the likelihood of changing vote choices. Other variables, such as interest and party identification strength, do not appear to affect the propensity of switching vote choice. The effect of the wave, as well, does not seem to be important in changing propensities to switch voting behaviour. This is consistent with the idea of a low-profile campaign that has been stressed above. It is important to underline that coefficients do not represent a simple association between people's characteristics but instead represent an estimate of the only within-individual variation. As pointed out above, this result is indeed much more robust than a simple between-individuals correlation.

Model 2 serves to dissect the effect seen in Model I, assessing whether the association between disagreement and vote switching holds for both intimate and non-intimate social relations. As evident for Model 2, the only association that holds is that among intimate people. As in Model I, no other effects significantly affect the likelihood of party switching. To assess the mag- 
Table 3: Three fixed-effect models for the study of vote switching

\begin{tabular}{|c|c|c|c|c|c|c|}
\hline \multirow[b]{2}{*}{ Dependent variable: Party switching } & \multicolumn{2}{|c|}{ Model 1} & \multicolumn{2}{|c|}{ Model 2} & \multicolumn{2}{|c|}{ Model 3} \\
\hline & Coef. & S.E. & Coef. & S.E. & Coef. & S.E. \\
\hline Disagr. with disc. at t-1 - ref. Agreement (DISAG $t_{t-1}$ ) & $0.51^{\star \star \star}$ & $(0.19)$ & $0.58^{* *}$ & $(0.24)$ & 0.56 & $(0.53)$ \\
\hline Disc. circle at t-1: Non-relative - ref. Relative (SOC_CIR $\left.\mathrm{t}_{\mathrm{t}-1}\right)$ & -0.27 & $(0.26)$ & -0.17 & $(0.35)$ & -0.23 & $(0.26)$ \\
\hline Disc. circle * Disc. Disagreement $\left(\mathrm{DISAG}_{\mathrm{t}-1} * \mathrm{SOC} \_C I R_{\mathrm{t}-1}\right)$ & & & -0.16 & $(0.37)$ & & \\
\hline Wave - continuous (WV) & & & & & -0.03 & $(0.09)$ \\
\hline Disc. disagreement * Wave (DISAG $\mathrm{t}-1 * \mathrm{WV})$ & & & & & -0.01 & $(0.12)$ \\
\hline Strength of party Id. at t-1 (PID_STRENGTH ${ }_{\mathrm{t}-1}$ ) & -0.19 & $(0.21)$ & -0.19 & $(0.20)$ & -0.17 & $(0.20)$ \\
\hline Interest in the outcome of the elections (INTER $R_{t}$ ) & 0.19 & $(0.19)$ & 0.19 & $(0.19)$ & 0.16 & $(0.18)$ \\
\hline \multicolumn{7}{|l|}{ Wave - ref. wave 2 (Wv) } \\
\hline Wave 3 & -0.31 & $(0.23)$ & -0.31 & $(0.23)$ & & \\
\hline Wave 4 & -0.35 & $(0.24)$ & -0.35 & $(0.24)$ & & \\
\hline Wave 5 & -0.22 & $(0.24)$ & -0.21 & $(0.24)$ & & \\
\hline Wave 6 & -0.17 & $(0.24)$ & -0.18 & $(0.24)$ & & \\
\hline Log Likelihood & \multicolumn{2}{|c|}{-243.0} & \multicolumn{2}{|c|}{-242.9} & \multicolumn{2}{|c|}{-244.3} \\
\hline Observations & \multicolumn{2}{|c|}{668} & \multicolumn{2}{|c|}{668} & \multicolumn{2}{|c|}{668} \\
\hline Number of individuals & \multicolumn{2}{|c|}{202} & \multicolumn{2}{|c|}{202} & \multicolumn{2}{|c|}{202} \\
\hline
\end{tabular}

Standard errors in parentheses

${ }^{* * *} p<0.01,{ }^{* *} p<0.05,{ }^{*} p<0.1$

Figure 2: Marginal effects for the effect of disagreement on vote switching-Models 1 (left panel) and 2 (right panel) estimates

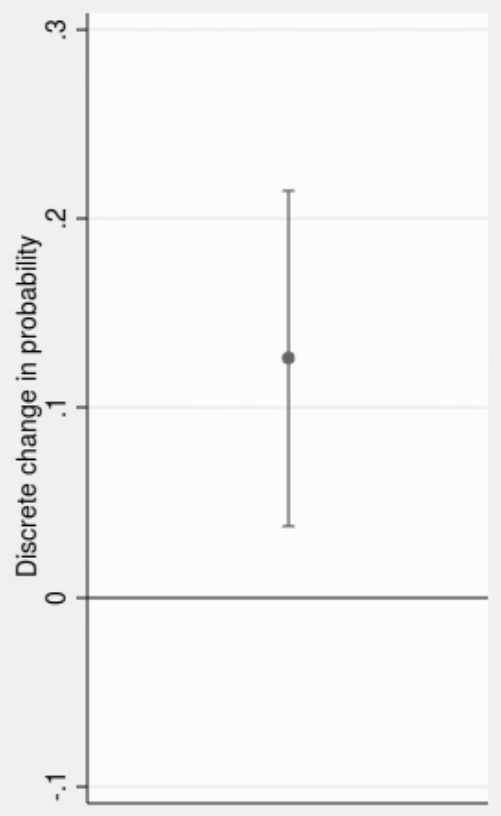

Whole sample

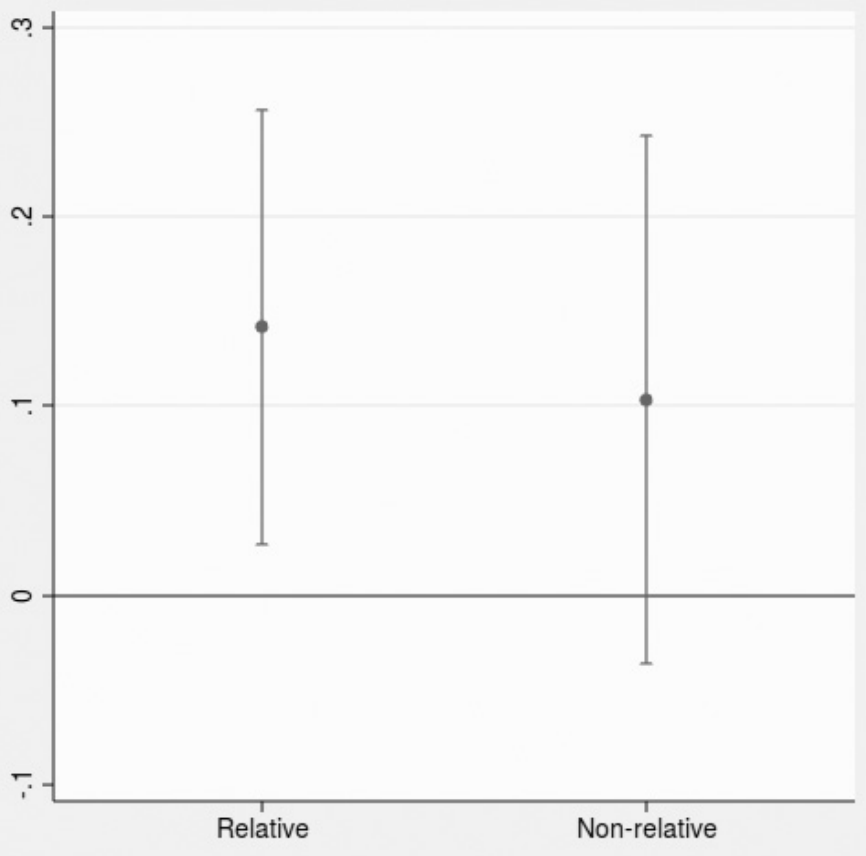

Main discussant's social circle 
nitude of the effects, Figure 2 presents marginal effects for the associations in Models I and 2. In the left panel, we see that situation of disagreement in $t-I$ leads to a more-than-Io percentage points higher likelihood to switch party. In the right panel, we see how the effect becomes slightly bigger (about 15 percentage points difference) only for people who are in disagreement with a relative. Disagreement with non-relatives, from the other side, does not lead to a significant increase in the likelihood of vote switching.

Model 3 allows us to investigate the relation between the acceleration of the campaign and the effect of influence. When the campaign accelerates, we can expect that political communication becomes more central, the likelihood of experiencing disagreement increases and attempts to recompose a situation of agreement among one's social network become stronger. The interaction between the wave number and disagreement, which is not statistically significant, suggests that at least according to data for the 2009 campaign, this process is not visible. This is consistent with what we have stressed above, that is, the relative failure of parties in activating the electorate and, in particular, the failure of the two major parties (the CDU and SPD) to engage themselves in an aggressive campaign, given the fact that both had participated in forming the grand coalition of the 20052009 period.

\section{Conclusion and discussion}

The present work was aimed at testing a micro-sociological process that is crucial in shaping patterns of political communication among citizens during an election campaign. Interpersonal influence was hypothesized here to affect the electoral behaviour of German voters during the 2009 election campaign. In particular, a positive relation was expected between disagreement in one wave and vote switching in the subsequent one. Consistent with previous literature, this relation was argued to be an indirect proof of the process of influence. The relation between disagreement and vote switching is usually argued in a network fashion. Recent studies (Bello/Rolfe 2OI4) stress the relation between overall network disagreement and the propensity of individual voters to switch to another party. However, this study argued that the overall disagreement in a network, if it leads to vote switching, can be experienced by the individual at the dyadic level. In other words, it is implied by the literature that individuals who are embedded in disagreeing networks are exposed to disagreeing dyads and, consequently, converted to voting for another party. This work focused on this implied consequence of the theory by testing, at the dyadic level, whether disagreement between a voter and his/her main discussant leads to a change of vote later.
In addition, it was hypothesized that the process of influence could be boosted by the exposure to main discussants who are relatives rather than non-relatives. As stressed in several previous works (Huckfeldt et al. 1995; Huckfeldt et al. 2004), this is because it is more difficult to sustain disagreement over time with strong ties. It is important to stress that this expectation, when confronted with the interpersonal influence process, has received little empirical treatment in the literature.

Thirdly, we expected that the election campaign, and especially closeness to the election day, by increasing political communication and the salience of political topics in public opinion, could influence the way in which people are influenced by (or influence) their discussants.

From the methodological side, it was stressed that the work tests the hypotheses by means of a technique fixed-effect regression - that has been rarely used in works on interpersonal influence and communication, although it leads to more robust results by relying only on within-individual variations and thus avoiding a number of alternative explanations.

Results partially confirm our hypotheses. As in other works, the relation between disagreement in a wave and vote switching in the following one can be assessed. This was true even when using fixed-effect models, with the aforementioned set of stronger assumptions with respect to pooled/multilevel models. The expectation according to which stronger ties exert a stronger influence effect on individuals was confirmed as well. People exposed to relatives (who are assumed to have, on average, more intimate relationships with their discussants; see Huckfeldt et al. 1995; Erisen/Erisen 20I2) have significant propensities to switch their vote, once exposed to disagreeing relatives. The propensity is not significantly higher for those who are exposed to non-relatives.

Finally, it was not apparent that any effect leads to an increase in influence during the campaign and especially during the end of the campaign, when political communication and interest in politics should be at their peak. This result can be explained through the nature of our case study, the 2009 Bundestag Campaign, in which major parties failed to mobilize their voters, given that they contributed to the grand coalition that had governed the country since 2005 .

The work presents at least three major limitations. First, although the fixed-effect model accounts for more reliable and robust estimates, we must not forget that this technique controls only for time-constant unobservable variables. The design, in addition, take into account only respondents' characteristics, without considering discussants' ones. In the case of an omitted time-varying, or discussant-related variable, our estimates could be biased (see Mancosu/Vezzoni 20I7b). 
The GLES short-term panel, moreover, presents only data for one discussant (what we have called the main discussant) and does not provide information for the larger network. This led us to interpret in a dyadic fashion the theory behind influence mechanisms. Although it has been stressed that a systematic effect of disagreement on vote switching would have tested influence process more subtly, we cannot deny that the dyadic influence effect that we see could also be affected by general consensus towards the switching of the broader social network. In other words, our coefficients could be affected by situations in which autoregressive influence (Huckfeldt et al. 2004) plays a major role in convincing ego to switch vote choices.

Finally, as stressed above, results present a clear issue given by the non-directionality of the models: we can only know whether disagreeing with their alters leads people to be more volatile (namely, changing vote choice) in the following wave, but we do not know whether this volatility is directed towards the party that alter actually voted for. More refined and complete data and models may account for this drawback in the future.

\section{References}

Allison, Paul D. (2009), Fixed Effects Regression Models, Los Angeles, CA: Sage.

Berelson, Bernard/Paul F. Lazarsfeld/William N. McPhee (1954), Voting: A Study of Opinion Formation in a Presidential Campaign, Chicago: University of Chicago Press.

Bello, Jason/Meredith Rolfe (2014), Is influence mightier than selection? Forging agreement in political discussion networks during a campaign, in: Social Networks, 36(I), I34-I46.

Budge, Ian/Ivor Crewe/Dennis Farlie (2010), Party identification and beyond. Representation of voting and party competition, Colchester: ECPR Press.

Campbell, Angus/Philip E. Converse/Warren E. Miller/ Donald E. Stokes (1960), The American voter, New York: John Wiley \& Sons.

Converse, Philip E. (I966), The concept of a normal vote, in: A. Campbell, P.E. Converse, W.E. Miller, D.E. Stokes (Eds.), Elections and the Political Order, New York: Wiley and Sons., 9-39.

Christakis, Nicholas A./James H. Fowler (2007), The spread of obesity in a large social network over 32 years, in: New England journal of medicine, 357(4), 370-379.

Christakis, Nicholas A./James H. Fowler (2008), The collective dynamics of smoking in a large social network, in: New England journal of medicine, 358(2I), 2249-2258.

Dilliplane, Susanna (2014), Activation, conversion, or reinforcement? The impact of partisan news exposure on vote choice, in: American Journal of Political Science, 58(I), 79-94.

Erisen, Elif/Cengiz Erisen (2012), The effect of social networks on the quality of political thinking, in: Political Psychology, 33(6), 839-865.

Faas, Thorsten/Rudiger Schmitt-Beck (20I0), Voters' political conversations during the 2005 German parliamentary election campaign, in: Wolf, M., Morales, L., Ikeda, K. (Eds.), Political Discussion in Modern Democracies: A Comparative Perspective, Abingdon: Routledge, 99-II6.

Festinger, Leo (I957), A Theory of Cognitive Dissonance, Stanford: Stanford University Press.

Fowler, James H./Michael T. Heaney/ David W. Nickerson/ John F. Padgett/Betsy Sinclair (20II), Causality in political networks, in: American Politics Research, 39(2), 437-480.

Gelman, Andrew/Gary King (1993), Why are American presidential election campaign polls so variable when votes are so predictable?, in: British Journal of Political Science, 23(4), 409-45I.

Granovetter, Mark S. (1973), The strength of weak ties, in: American journal of sociology, 78(6), I360-I380.

Hopmann, David N. (2OI2), The Consequences of Political Disagreement in Interpersonal Communication: New Insights from a Comparative Perspective, in: European Journal of Political Research. 5I(2), 265-287

Huckfeldt, Robert/John Sprague (1995), Citizens, politics and social communication: Information and influence in an election campaign, New York: Cambridge University Press.

Huckfeldt, Robert/Paul E. Johnson/John Sprague (2004), Political disagreement: The survival of diverse opinions within communication networks, Cambridge: Cambridge University Press.

Huckfeldt, Robert/Ken'ichi Ikeda/Franz U. Pappi (2005), Patterns of disagreement in democratic politics: comparing Germany, Japan, and the United States, in: American Journal of Political Science, 49, 497-5I4.

Huckfeldt, Robert/Paul A. Beck/Russel J. Dalton/Jeffrey Levine (1995), Political environments, cohesive social groups, and the communication of public opinion, in: American Journal of Political Science, 39(4), IO25-IO54.

Jackman, Simon/ Lynn Vavreck (20IO), Primary politics: race, gender and age in the 2008 democratic primary, in: Journal of Elections, Public Opinion \& Parties, 20(2): I53-I86.

Johnston, Richard/Julia Partheymüller/Rudiger SchmittBeck (20I4), Activation of Fundamentals in German Campaigns, in: Bernhard Weßels, Hans Rattinger, Sigrid Roßteutscher, Rüdiger Schmitt-Beck (Eds.), Voters on the Move or on the Run?, Oxford: Oxford University Press, 217-237.

Klofstad, Casey A. (2007), Talk Leads to Recruitment How Discussions about Politics and Current Events In- 
crease Civic Participation, in: Political Research Quarterly, 60(2), I80-I9I.

Klofstad, Casey A./Scott D. McClurg/Meredith Rolfe (2009), Measurement of Political Discussion Networks A Comparison of Two "Name Generator" Procedures, in: Public Opinion Quarterly, 73(3), 462-483.

Krewel, Mona/Rudiger Schmitt-Beck/Ansgar Wolsing(20II), The Campaign and its Dynamics at the 2009 German General Election, in: German Politics 20, 28-50.

Krosnick, Jon A./Donald R. Kinder (1990), Altering the foundations of support for the president through priming, in: American Political Science Review, 84(2), 497-5I2.

Lazarsfeld, Paul F./Bernard Berelson/Hazel Gaudet (1968), The People's Choice: How the Voter Makes up his Mind in a Presidential Campaign, New York/London: Columbia University Press.

Latané, Bibb (1996), Dynamic social impact: the creation of culture by communication, in: Journal of Communication, 46,13

Lazer, David (2OII), Networks in political science: back to the future, in: PS: Political Science and Politics, $4 \mathrm{I}(\mathrm{I})$, 6I-68.

Lomi, Alessandro/Tom A.B. Snijders/Christian E.G. Steglich/Vanina J. Torló (20II), Why are some more peer than others? Evidence from a longitudinal study of social networks and individual academic performance, in: Social Science Research, 40(6), 1506-1520.

Lyons, Russell (2OII), The spread of evidence-poor medicine via flawed social-network analysis, in: Statistics, Politics, and Policy, 2(I), I-27.

Mancosu, Moreno/Cristiano Vezzoni (20I7), "Blood Is Thicker Than Water": Interpersonal Influence, Selection, and the Role of Family in Forging Italians' Political Agreement, in: International Journal of Communication, II, 647-668.

Mancosu, Moreno/Cristiano Vezzoni (2017b), Actor-Partner Interdependence Models (APIM) and Voting Behavior: Methodology and Applications, in: Political Psychology. Early view.

Mollenhorst, Gerald/Beate Volker/Henk Flap (2008), Social contexts and core discussion networks, in: Social Forces, 86, 937-965.

Mutz, Diana (2002), The consequences of cross-cutting networks for political participation, in: American Journal of Political Science 46(4), 838-855.

Mutz, Diana/Jeffrey J. Mondak (2006), The workplace as a context for cross-cutting political discourse, in: The Journal of Politics, 68(I), I4O-I55.

Noel, Hans/Brendan Nyhan (2OII), The "unfriending" problem: The consequences of homophily in friendship retention for causal estimates of social influence, in: Social Networks, 33(3), 21I-218.

Partheymüller, Julia/Rudiger Schmitt-Beck (2012), A 'Social Logic' of Demobilization: The Influence of Political
Discussants on Electoral Participation at the 2009 German Federal Election, in: Journal of Elections, Public Opinion \& Parties, 22(4), 457-478.

Rolfe, Meredith (2009), Conditional choice processes, in: Bearman, P., Hedström, P. (Eds.), Oxford Handbook of Analytical Sociology, Oxford University Press, Oxford: 419-436.

Rolfe, Meredith (2012), Voter Turnout: A Social Theory of Political Participation. Cambridge University Press, New York.

Schmitt-Beck, Rudiger/Evelyn Bytzek/Hans Rattinger/Sigrid Roßteutscher/Bernard Weßels (2009), The German Longitudinal Election Study (GLES). Paper presented at the annual meeting of International Communication Association (ICA), Chicago, May 2I-25.

Schmitt-Beck, Rudiger/ Julia Partheymüller (2016), A twostage theory of discussant influence on vote choice in multiparty systems, in: British journal of political science, $46(2), 32 \mathrm{I}-348$.

Siddiqui, Ohidul/M. W. Ali (1998), A comparison of the random-effects pattern mixture model with lastobservation-carried-forward (LOCF) analysis in longitudinal clinical trials with dropouts, in: Journal of Biopharmaceutical Statistics, 8(4), 545-563.

Wooldridge, Jeffrey (2012), Introductory econometrics: A modern approach, Boston: Cengage Learning.

Zaller, John (1992), The Nature and Origins of Mass Opinion, Cambridge: Cambridge University Press.

Zuckerman, Alan S. (Ed.). (2005), The social logic of politics: Personal networks as contexts for political behaviour, Philadelphia: Temple University Press.

\section{Author}

Moreno Mancosu is a post-doctoral fellow at Collegio Carlo Alberto, Turin. His recent publications include 'Contexts, networks, and voting behaviour: The social flow of political communication in Italy', Italian Political Science Review (20I6); and 'Actor-Partner Interdependence Models (APIM) and voting behaviour: Methodology and applications', Political Psychology. 
